\title{
Safety and immunogenicity of a paediatric presentation of an influenza vaccine
}

\author{
M Gonzalez, M C Pirez, E Ward, H Dibarboure, A García, H Picolet
}

\begin{abstract}
Background-Flu vaccination in otherwise healthy infants and young children is important to prevent severe disease, as well as to control epidemic spread of influenza infection.

Aims-To examine the safety and immunogenicity of a paediatric presentation of a purified, inactivated, triton split influenza vaccine.

Methods-Two doses of the vaccine, provided in prefilled syringes of $0.25 \mathrm{ml}$, were administered, one month apart, to 67 children under 3 years of age.

Results-Nine cases of immediate reaction to vaccination (macules/papules) were observed after the second injection only. During the study period, $9 \%$ of children experienced at least one delayed local reaction, and $28 \%$ of children presented at least one systemic reaction. Almost all reactions were mild and transient. Immunogenicity results surpassed the European Community recommendations for a $\mathbf{0 . 5 0}$ $\mathrm{ml}$ dose of vaccine in adults.

Conclusion-This paediatric formulation of inactivated flu vaccine appears safe and immunogenic in children from 6 months to 3 years of age; the convenient presentation in a prefilled syringe of $0.25 \mathrm{ml}$ volume will facilitate administration of the dose recommended for young children.

(Arch Dis Child 2000;83:488-491)
\end{abstract}

Keywords: influenza; influenza vaccine; immunogenicity; safety

\section{Centro}

Materno-Infantil

Maciel, Montevideo,

Uruguay

M Gonzalez

M C Pirez

E Ward

Aventis Pharma, Medical Department, Montevideo

H Dibarboure

Aventis Pasteur International, 2, avenue Pont Pasteur, 69007 Lyon, France

A García

H Picolet

Correspondence to: Dr Garcia

Accepted 31 May 2000 and results in substantial morbidity in children under 3 years of age. Children attending kindergarten, day care centres, or other institutions are particularly at risk of becoming infected with the influenza virus and are the main disseminators of viruses during epidemics. Infants and young children, even without chronic or serious medical conditions, are clearly at increased risk for severe disease, and should be considered as targets for regular vaccination against influenza. ${ }^{9}$

The viruses responsible for influenza epidemics change yearly. On the basis of the circulating strains identified, health authorities issue recommendations each February for the antigens to be represented in the influenza vaccine for the northern hemisphere. From 1998, a second set of recommendations has also been issued in September for the antigens to be included in the influenza vaccine for the southern hemisphere. In general, the influenza vaccine is trivalent and includes two subtypes of the type A strain (H3N2 and H1N1) and one type B strain.

In 1969, the Institut Mérieux (now Aventis Pasteur) developed a split influenza vaccine grown on embryonated chicken eggs, ${ }^{10}$ and the current formulation has been marketed since 1995. ${ }^{11}{ }^{12}$ The vaccine is presented in prefilled syringes of $0.5 \mathrm{ml}$, which corresponds to the recommended adult dose. Despite some data indicating that the immune response to influenza vaccine in young children is weaker than in adults, ${ }^{13}$ two 1995 studies established that this vaccine was safe and immunogenic in a group of 106 children aged between 3 and 10 years of age. ${ }^{12} 14$

Although the recommended influenza vaccination schedule for children varies from country to country, two $0.25 \mathrm{ml}$ doses (that is, half of the adult dose), administered one month apart, are now recommended for children below 3 years of age by the American Advisory Committee on Immunization Practices (ACIP). ${ }^{1}$ As most manufacturers supply a ready to use adult dose of their influenza vaccines, health care personnel are obliged to vaccinate young children with half of the volume provided-a procedure that wastes product and may result in errors in manipulation. In order to facilitate the administration of flu vaccine to children, Aventis Pasteur has developed prefilled syringes that contain 0.25 $\mathrm{ml}$ of the adult formulation. The aim of the present study was to examine the safety and immunogenicity of this paediatric presentation of purified, inactivated, triton split flu vaccine in children between 6 months and 3 years of age. 
Subjects and methods

This open, uncontrolled study was conducted between March and June 1996 at a mother and infant centre in Montevideo, Uruguay. The protocol followed the European Community recommendations for the clinical evaluation of influenza vaccines ${ }^{15}$ and was approved by the Ethics Committee of the Maciel Mother and Infant Center, Maciel Hospital.

Children between 6 months and 3 years of age having no contraindications for flu immunisation were included. Written consent from at least one parent or guardian of each child was obtained. Exclusion criteria included: immunodepression; known allergy to any vaccine component (for example, egg protein); signs of an infection or fever (axillary temperature above $38^{\circ} \mathrm{C}$ ) in the 72 hours preceding inclusion, previous influenza or any other vaccinations, or $\gamma$ globulin treatment in the four weeks preceding inclusion; long term treatment with corticosteroids; treatment with pituitary hormone extract; participation in another clinical trial; or possibility of noncompliance with the study protocol.

The 95/96 formulation of the purified, inactivated, triton split influenza vaccine (batch S3229, Aventis Pasteur, Lyon, France) contained, per $0.25 \mathrm{ml}$ dose, $7.5 \mu \mathrm{g}$ of haemagglutinin (HA) from each of an A/Johannesburg/ 33/94 (H3N2) like strain, an A/Singapore/6/86 (H1N1) like strain (A/Texas/36/91), and a B/Beijing/184/93 like strain (B/Harbin/7/94). (The adult formulation contains $15 \mu \mathrm{g}$ HA per influenza virus vaccine strain.) The vaccine also contained sodium mercurothiolate $(\leqslant 0.025 \mathrm{mg})$ and formaldehyde $(\leqslant 0.05 \mathrm{mg})$, and was presented in a buffered saline solution (up to $0.25 \mathrm{ml}$ )

The vaccine, stored between $2^{\circ} \mathrm{C}$ and $8^{\circ} \mathrm{C}$ and presented in a prefilled syringe, was administered by intramuscular injection into the anterolateral aspect of the thigh or into the deltoid using a 25 gauge, $16 \mathrm{~mm}$ needle. Precautions were taken to ensure that the vaccine was administered intramuscularly (vein test).

Children complying with our requirements for inclusion into the study, and having none of the exclusion criteria, received two doses of the vaccine, one month apart. They were monitored for 15 minutes after each injection to detect any immediate reactions. Any local and systemic reactions occurring after this immediate observation period, but within the first three days of vaccination, and then between days 4 and 30, were monitored by the parents who used diaries and were subsequently interviewed during each visit to the mother and infant centre. Any serious or unexpected undesirable effect was reported immediately to the investigator.

A first blood sample was taken immediately before the first vaccination, and the second sample was drawn 27 to 33 days after the last vaccination. Serum samples were frozen at $-20^{\circ} \mathrm{C}$ and transported in insulated containers by air to the Aventis Pasteur Clinical Seroimmunology Laboratory (Val de Reuil, France), where all analyses were performed under masked conditions. Serum antibody concentrations to each of the three strains were assessed by a haemagglutination inhibition (HI) assay. Antibody titres were defined as the reciprocal of the highest dilution of serum that inhibited haemagglutination by the specific virus. A titre of $\geqslant 40$ was considered protective, while seroconversion was defined either as: a fourfold increase in the prevaccination titre; or as an undetectable titre $(<10)$ reaching a protective concentration.

Data analysis was descriptive and performed using SAS software (version 6.08, Cary, North Carolina, USA).

\section{Results}

Sixty seven children were included in the study between March and April 1996. (A prevaccination blood sample could not be obtained from two children who were subsequently excluded from the study.) Of the 65 children who received the first vaccine injection, 16 (25\%) did not complete the study. The reason for withdrawal was established for 12 of these drop outs and included a change in residence (seven cases) or another logistic reason (one case), subject age exceeding 3 years (two cases), and medical reasons independent of the study (two cases). The analysis of immediate safety was performed on all children who received at least one dose of the vaccine ( 65 children for the first injection, and 57 for the second); the analysis of systemic and local reactions included all children who attended the follow up visit (57 after the first dose, and 50 after the second). Pre- and post-vaccination antibody titres against the three viral strains were available for 49 children.

Table 1 presents the age and sex characteristics of the children who received the first dose of the vaccine and those who completed the study. There was a majority of boys; the average age of the subjects was approximately 20 months.

The only immediate reactions observed were local - nine cases of injection site macules or papules after the second immunisation, which were characteristic of an allergic rash to vaccination (table 2). Following the 15 minute observation period, in total, only seven delayed local reactions were reported over the next three days in five children (9\%). These reactions mostly consisted of reddened papules, diameter of affected area less than $3 \mathrm{~cm}$, with three children developing this reaction after each injection. In addition, one child suffered from severe pain (preventing voluntary movement of the vaccinated limb) from day 0

Table 1 Age and sex characteristics of children enrolled in a safety and immunogenicity study of two doses of a paediatric presentation of triton split, inactivated flu vaccine at the time of inclusion and at study completion

\begin{tabular}{lll}
\hline & $\begin{array}{l}\text { At time of first dose } \\
(n=65)\end{array}$ & $\begin{array}{l}\text { At study completion } \\
(n=49)\end{array}$ \\
\hline $\begin{array}{l}\text { Number (\%) of males } \\
\text { Age (months) }\end{array}$ & $37(57 \%)$ & $31(63 \%)$ \\
$\quad$ Min-max & $6-42$ & $6-39$ \\
Mean (SD) & $20.8(11.3)$ & $19.9(10.1)$ \\
\hline
\end{tabular}


Table 2 Number (\%) of children aged from 6 months to 3 years with adverse events following immunisation with two doses of a paediatric presentation of a triton split, inactivated flu vaccine given one month apart

\begin{tabular}{llll}
\hline & $\begin{array}{l}\text { Following } \\
\text { injection 1 }\end{array}$ & $\begin{array}{l}\text { Following } \\
\text { injection 2 }\end{array}$ & $\begin{array}{l}\text { Entire study } \\
\text { period }\end{array}$ \\
\hline Immediate reactions $\dagger$ & & & \\
$\quad$ Local & $0 / 65$ & $9 / 57(16 \%)$ & $9 / 65(14 \%)$ \\
$\quad$ Systemic & $0 / 65$ & $0 / 57$ & 0 \\
Local reactions $\ddagger$ & $4 / 57(7 \%)$ & $3 / 50(6 \%)$ & $5 / 57(9 \%)$ \\
At least one systemic & & & \\
$\quad$ event & $9 / 57(16 \%)$ & $9 / 50(18 \%)$ & $16 / 57(28 \%)$ \\
Serious adverse events & $1^{\star}$ & 0 & $1^{\star}$
\end{tabular}

${ }^{\star}$ Considered unrelated to the vaccine.

+Within 15 minutes after each injection.

$\$$ Within three days after each injection.

to day 2 following the first injection. This was merely a painful reaction, and was not associated with any signs of hypersensitivity.

Eighteen systemic events were observed in nine children after the first injection, and 12 events were seen in nine children after the second injection (table 2). The symptoms noted were mostly rhinitis and cough, which accounted for 10 events after the first injection and for nine events after the second injection. Four cases of fever (between $38.5^{\circ} \mathrm{C}$ and $38.9^{\circ} \mathrm{C}$, axillary temperature) were observed after the first injection, and one febrile episode was reported after the second injection.

Systemic events between days 4 and 30 were experienced by 30 children after the first injection and by 37 children after the second injection. These were common childhood events and were not likely to have been related to the vaccine.

One serious adverse event occurred during the study. A 1 year old girl with a past history of bronchiolitis was hospitalised for bronchospasm 25 days after the first vaccine injection. She recovered after a two day treatment with salbutamol and prednisolone. She received the second vaccine injection 10 days later and presented with a mild bronchospasm, which did not need specific therapy, 27 days after vaccination. The event was considered by the investigator to be unrelated to vaccination.

Table 3 summarises the immunogenicity results for each strain of vaccine virus, 30 days after the second injection. The responses to all three strains were good, with protective con-

Table 3 Results of the haemagglutination inhibition assay $(n=49)$

\begin{tabular}{|c|c|c|}
\hline & Pre-vaccination & Post-vaccination \\
\hline $\begin{array}{l}\mathrm{A} / \mathrm{Johannesburg} / 33 / 94(\mathrm{H} \\
\text { Seroconversion: } \mathrm{n}(\%) \\
\text { Protective level: } \mathrm{n}(\%) \\
\text { GMT }(95 \% \mathrm{CI})\end{array}$ & $\begin{array}{l}\overline{19}(38.8) \\
17.9(11.2-28.5)\end{array}$ & $\begin{array}{l}41(83.7) \\
45(91.8) \\
175(114-269)\end{array}$ \\
\hline $\begin{array}{l}\text { A/Singapore/6/86 (H1N1) } \\
\text { Seroconversion: } \mathrm{n}(\%) \\
\text { Protective level: n }(\%) \\
\text { GMT }(95 \% \mathrm{CI})\end{array}$ & $\begin{array}{l}6 / 91) \\
\frac{0}{5.0(5.0-5.0)}\end{array}$ & $\begin{array}{l}40(81.6) \\
40(81.6) \\
66.4(51.6-85.4)\end{array}$ \\
\hline $\begin{array}{l}\text { B/Beijing/184/93 like strai } \\
\text { Seroconversion: } \mathrm{n}(\%) \\
\text { Protective level: } \mathrm{n}(\%) \\
\text { GMT }(95 \% \mathrm{CI})\end{array}$ & $\begin{array}{l}\overline{13}(26.5) \\
21.9(17.3-27.6)\end{array}$ & $\begin{array}{l}30(61.2) \\
46(93.9) \\
88.7(71.8-110)\end{array}$ \\
\hline
\end{tabular}

Results express number (percentage) of children aged from 6 months to 3 years immunised with two doses of a paediatric presentation of a triton split, inactivated flu vaccine given one month apart, who seroconverted to each strain 30 days after second dose, and achieved protective antibody titres ( $\mathrm{HI} \geqslant 40$ units), and pre- and post-vaccination geometric mean titre (GMT) values with $95 \%$ confidence intervals (CI).

Protective level was defined as a titre $\geqslant 40$. Seroconversion was defined as a fourfold rise versus pre-vaccination titre or an undetectable titre reaching a value $\geqslant 40$. centrations of antibodies achieved by $81.6-$ $93.9 \%$ of the children, depending on the strain. The geometric mean titres increased from preimmunisation concentrations by a factor of 9.8 for the $\mathrm{A} / \mathrm{H} 3 \mathrm{~N} 2$ strain, 13.3 for the $\mathrm{A} / \mathrm{H} 1 \mathrm{~N} 1$ strain, and 4.1 for the B strain. The increase in titres following immunisation complied fully with European Community recommendations for young adults. ${ }^{15}$

\section{Discussion}

Children less than 5 years of age are the second highest risk group, after the elderly, for severe influenza disease, with annual hospitalisation rates per 100000 population of about 500 and 100 for those with and without underlying high risk conditions, respectively. ${ }^{1}$ Although systematic flu vaccination has so far been recommended only for infants at high risk of developing complications to influenza (for example, those suffering from serious respiratory or heart problems), vaccinating healthy children attending nurseries and day care centres may avoid epidemic situations, ${ }^{16}$ and very young children have been shown to be at increased risk of hospitalisation during influenza seasons. ${ }^{67}$ Moreover, acute otitis media is a known common complication of influenza A infection in otherwise healthy children. ${ }^{17}$ Two studies have shown that influenza vaccination in day care children aged from 6 months of age was associated with a significant reduction in the incidence of otitis media during a flu season. $^{18} 19$

We evaluated the safety and immunogenicity of a paediatric presentation of a trivalent split inactivated influenza vaccine in children aged from 6 months to 3 years. Children enrolled in this study were healthy and presented no contraindications to flu vaccination.

Although 65 children received the first influenza vaccine injection, only 49 (75.4\%) completed the study follow up. This moderate compliance with the study protocol may be partly explained by the low income and lack of a permanent residence of the study subjects in Uruguay. As reasons for loss to follow up were known in most cases and were not related to the influenza vaccine, it should not have introduced any bias into the immunogenicity and safety results.

The vaccine was well tolerated. In the three days following either the first or the second injection, delayed local reactions were reported by $7 \%$ and $6 \%$ of children, respectively, and systemic reactions by $16 \%$ and $18 \%$, respectively. Immediate reactions-that is, those reported within 15 minutes after vaccination, characteristic of an allergic rash, increased with subsequent doses (zero after the first dose, nine after the second dose). While this observation does suggest that some children were hypersensitive to the second vaccine dose, none of the reactions were severe, and all subsided spontaneously. There was no vaccine related serious adverse event reported during this study.

The immune response to influenza vaccine is known to vary between age groups. In particular, a weaker immune response has been observed in infants and in the elderly. ${ }^{1320}$ In 
addition, severe illnesses that induce immune deficiency (for example, cancer or AIDS) appear to reduce the response to the vaccine significantly. ${ }^{21-23}$ Nevertheless, immunogenicity results for infants and young children (6 months to 3 years old) in this study were found to be as good or better than those observed in children ( 3 to 10 years old) and adults. ${ }^{14}$ Moreover, the seroconversion rates, seroprotection rates, and the geometric mean of the haemagglutination inhibition titres for antibodies to the three viral strains measured in our series of children were above the European Community recommendations for influenza vaccine in young adults. ${ }^{15}$

This study was conducted in the southern hemisphere autumn (between March and May) and outside the typical flu season, which usually starts in May. The results obtained are thus not likely to be a result of natural flu virus eliciting antibody titres. In addition, the absence of any flu like syndrome in any of the contacts of the study children also supports the exclusion of natural infection from these results.

Our results are in contrast to those reported by Groothuis et al, who studied the immunogenicity and safety of a split influenza vaccine in 6-18 month old infants; a low humoral immune response to some viral antigens was observed. ${ }^{13}$ It should be noted, however, that the children included in that study were mainly premature infants with bronchopulmonary dysplasia.

CONCLUSIONS

The effectiveness of flu vaccination will vary with the degree of match between vaccine and circulating viral strains, and will be liable to vary from year to year. Nevertheless, it is important to show, for those strains recommended, that any vaccine can elicit antibody concentrations capable of protecting against infection. In our study, we found that two 0.25 $\mathrm{ml}$ injections of a purified, triton split, inactivated influenza vaccine are safe and immunogenic in apparently influenza unprimed, healthy children between 6 months and 3 years of age. The convenient presentation of this vaccine in a prefilled, $0.25 \mathrm{ml}$ syringe will allow medical personnel to give the exact dose recommended for young children, while avoiding errors in manipulation and eliminating product wastage.

1 CDC. Prevention and control of influenza. Recommendations of the Advisory Committee on Immunization Practices (ACIP). Morbid Mortal Wkly Rep 2000;48(RR3): $1-38$
2 American Academy of Pediatrics. Report of the Committee on Infectious Diseases, 22nd edn. American Academy of Pediatrics, 1991:274-81.

3 Brydak LB, Frącka B, Marusak M, Rudnicka H, Nachman SA. Influenza immunization for children with bronchopulmonary dysplasia in Poland. Pediatr Infect Dis $\mathcal{f}$ 1997;16: 538-9.

4 Bydak LB, Rokicka-Milewska R, Machaa M, Jackowska T, Sikorska-Fic B. Immunogenicity of subunit trivalent influenza vaccine in children with acute lymphoblastic leukemia. Pediatr Infect Dis f 1998;17:125-9.

5 Safrin S, Rash JD, Mills J. Influenza in patients with human immunodeficiency infection. Chest 1990;98:33-7.

6 Maletic Neuzil K, Mellen BG, Wright PF, Mitchel EF Jr, Griffin MR. The effect of influenza on hospitalizations, outpatient visits and courses of antibiotics in children. $N$ Engl f Med 2000;342:225-31.

7 Izurieta HS, Thompson WW, Shay DK, et al. Influenza and the rates of hospitalization for respiratory disease among infants and young children. N Engl F Med 2000;342:232-9.

8 Ruuskanen O, Arola M, Putto-Laurila A, et al. Acute otitis media and respiratory virus infections. Pediatr Infect Dis $\mathcal{F}$ 1989;8:94-9.

9 Glezen P. Consideration of the risk of influenza in children and indications for prophylaxis. Rev Infect Dis 1980;2:40820 .

10 Brandon FB, Cox F, Quinn E, Timm EA, McLean IW Jr. Influenza immunization: clinical studies with ether-split subunit vaccines. Bull World Health Organ 1969;41:629-37.

11 Gross PA, Ennis FA, Gaerlan PF, Denning CR, Setia U, Davis WJ, Bisberg DS. Comparison of a new triton-X-100 and twenn-ether-treated split vaccines in children. $\mathcal{F}$ Clin Microbiol 1981;14:534-8.

12 Lina B, Fletcher MA, Valette M, Saliou P, Aymard M. A Triton-X-100-split influenza vaccine is safe and fulfills the European Agency for Evaluation of Medicinal Products recommendations for immunogenicity in children, adults and the elderly. Biologicals (in press).

13 Groothuis JR, Levin MJ, Rabalais GP, Meiklejohn G, Lauer BA. Immunization of high-risk infants younger than 18 months of age with split-product influenza vaccine. Pediatrics 1991;87:823-8.

14 Lina B, Valette M, Picolet H, Saliou P, Aymard, M. Safety and immunogenicity of an inactivated triton split influenza vaccine in different age groups. Vaccine (in press).

15 European Agency for the Evaluation of Medicinal Products/ Committee for Proprietary Medicinal Products (CPMP). Harmonization of requirements for influenza vaccines. London: Human Medicines Evaluation Unit, 1997:15-19.

16 Longini IM, Ackerman E, Elveback LL. An optimization model for influenza A epidemics. Math Biosci 1978;38:141-

17 Teele DW, Klein JO, Rosner B, Greater Boston Otitis Media Study Group. Middle ear disease and the practice of pediatrics: burden during the first five years of life. $\mathcal{F A M A}$ 1983;249:1026-9.

18 Heikkinen T, Ruuskanen O, Waris M, Ziegler T, Arola M, Halonen P. Influenza vaccination in the prevention of acute otitis media in children. Am 7 Dis Child 1991;145:445-8.

19 Clements DA, Langdon L, Bland,C, Walter E. Influenza A vaccine decreases the incidence of otitis media in 6- to 30-month old children in day care. Arch Pediatr Med 1995; 149:1113-17

20 Iorio AM, Zei T, Neri M, Campitellu L, Castrucci MR, Donatelli I. Immunization of elderly volunteers with the 1988-1989 inactive whole influenza vaccine: assessment of antibody responses by haemagglutination inhibition and single radial haemolysis tests. Eur f Epidemiol 1992;8:4917.

21 Steinherz P, Brown A, Gross P, et al. Influenza immunization in children with neoplastic diseases. Cancer 1980;45:750-6.

22 Allison JE, Glezen WP, Taber LH, Paredes A, Webster RG. Reactogenicity and immunogenicity of bivalent influenza A and monovalent influenza $B$ virus vaccine in high-risk children. F Infect Dis 1977;136:672.

23 Nelson KE, Clements ML, Miotti P, et al. The influence human immunodeficiency virus (HIV) infection on antibody responses to influenza vaccines. Ann Intern Med 1988;109:383-8. 